ORI GI NAL

\title{
ENFERMEDAD DE NEWCASTLE EN AVES DE TRASPATIO DEL EJE CAFETERO COLOMBIANO
}

\section{NEWCASTLE DI SEASE I N VI LLAGE CHI CKENS I N THE COLOMBIAN COFFEE AREA}

\author{
Marlyn Romero P, ${ }^{1 *}$ M.Sc, William Narvaez S, ${ }^{1}$ Ph.D, Jorge Sánchez V, ${ }^{1}$ M.Sc. \\ 1 Universidad de Caldas, Facultad de Ciencias Agropecuarias, Programa de Medicina \\ Veterinaria y Zootecnia, Departamento de Salud Animal. Calle 65 \#26-10, Manizales, \\ Colombia. Telefax: 8781516. E-mail: marlyn.romero@ucaldas.edu.co.
}

Recibido: Junio 23 de 2009; Aceptado: Agosto 25 de 2009

\section{RESUMEN}

Objetivo. Evaluar la circulación del virus de la enfermedad de Newcastle (ENC) en aves de traspatio de siete municipios del eje cafetero por medio de la técnica ELISA. Materiales y métodos. Fueron encuestados 465 predios para evaluar las normas de bioseguridad de las aves de traspatio de los municipios de Armenia, Circasia, Quimbaya, Montenegro, Filandia, Calarcá y La Tebaida del Departamento del Quindío. Se analizaron 662 muestras de suero para detectar anticuerpos IgG contra el virus de la ENC por ELISA. Resultados. La seroprevalencia de la ENC en la población de aves evaluada fue del 30.7\%.(203/662), que corresponde al 38.5\% de los predios encuestados. No se encontró asociación entre la especie y la seroreactividad $(p=0.21)$, ni entre la distribución de los anticuerpos por grupos productivos y la edad ( $p>0.05$ ). Los predios de traspatio son manejados de forma extensiva, albergan en las mismas instalaciones aves de diferentes especies y edades en el $64.3 \%$ (299/465), con edades en intervalos entre tres meses y cinco años. Fueron detectadas malas prácticas de manejo de la gallinaza y la mortalidad, sin encontrar asociación estadísticamente significativa entre las variables evaluadas y la presencia de anticuerpos anti-virus de ENC $(p>0.05)$. Conclusiones. Es necesario el establecimiento de planes adecuados de vacunación de las aves de traspatio, la vigilancia epidemiológica activa, la observación de los casos sospechosos, sin dejar de lado la educación y capacitación, sobre el adecuado manejo de los animales, dirigida a los propietarios de las aves como medidas de control de la enfermedad.

Palabras clave: Aves domesticas, enfermedad de Newcastle, prevalencia, Colombia. 


\section{ABSTRACT}

Objetive. To Evaluate the circulation of Newcastle virus disease (NVD) in village chickens from seven municipalities in the Colombian coffee area. Materials and Methods. 465 rural properties were surveyed to assess the biosecurity managements of village chickens in the Armenia, Circasia, Quimbaya, Montenegro, Filandia, Tebaida and Calarcá municipalities of the Quindio Department. 662 sera samples were analyzed by ELISA for detecting IgG antibodies against the NVD virus. Results. Seroprevalence of NVD in poultry was of $30.7 \%$ $(203 / 662)$ which corresponded to $38.5 \%$ of the rural properties. No association was found between the species and the seroreactivity $(p=0.21)$ nor between the distribution of antibody and age groups $(p>0.05)$. The village chicken farms are managed extensively, housed in the same backyards different species and ages in 64.3\% (299/465), with ages ranging between three months and five years. Poor management practices of poultry litter and mortality were identified; without finding statistically significant association between these variables and the presence of antibodies against NVD. Conclusions. It is necessary the establishment of adequate programs of vaccination for backyard birds, active surveillance, and observation of suspected cases and education of the owners of the village chickens as measures of disease control.

Key words: Chicken domestic, Newcastle disease, prevalence, Colombia.

\section{NTRODUCCIÓN}

La enfermedad de Newcastle (ENC) es una de las enfermedades más importantes de las aves, junto con la influenza aviar altamente patógena $(1,2)$. El agente etiológico es un virus ARN no segmentado, del género Avulavirus, subfamilia Paramyxovirinae y familia Paramyxoviridae (2). Es un agente altamente contagioso, que afecta cerca de 250 especies de aves (2). La importancia económica de la enfermedad radica en la disminución de la producción de los planteles avícolas afectados y la alta tasa de mortalidad, teniendo en cuenta que las cepas virulentas producen infecciones que pueden causar la muerte del $100 \%$ de las aves no vacunadas (3). Como medida de control de la enfermedad, por su eficacia, se ha establecido la vacunación rutinaria contra el virus de todas las aves comerciales. Sin embargo, las aves de traspatio no son sometidas a este procedimiento por razones sociales y económicas $(1,2)$. Se ha descrito la aparente resistencia de estas aves a la enfermedad, pero se reconoce que actúan como importantes portadores y fuentes de infección para la avicultura comercial $(4,5)$. Por lo tanto, en los programas de erradicación de la ENC es imperativo el control de la diseminación de la infección a través de estos reservorios y otras aves ornamentales $(1,3,6)$.

En Colombia la ENC presenta una alta prevalencia y se constituye en una de las tres enfermedades de control oficial por parte del Ministerio de Agricultura y Desarrollo Rural con el apoyo del Instituto Colombiano Agropecuario I.C.A. (6). Mediante la Ley de Sanidad Aviar (7) se ha propuesto un proyecto para la erradicación de la enfermedad que cuenta con la participación de los productores, basado en el fortalecimiento de la vacunación masiva de todas las aves susceptibles, la vigilancia epidemiológica y la destinación de los recursos financieros que garanticen el desarrollo de las actividades propuestas, entre otros aspectos. El eje cafetero se constituye en una región importante en el mercado interno de la industria avícola nacional, participando con el $7 \%$ de la producción de pollo y el $4 \%$ del huevo comercial (6). En esta zona se encuentran distribuidas una gran variedad de explotaciones de traspatio que aún no han sido caracterizadas. Dentro de este 
contexto, es de vital importancia ampliar la cobertura de la vigilancia epidemiológica activa en aves de traspatio o de autoconsumo, motivo por el cual se plantearon como objetivos del presente estudio caracterizar la población de traspatio del departamento de Quindío y evaluar la circulación del virus de NC por medio de la técnica de inmunoensayo ligado a enzimas (ELISA).

\section{MATERI ALES Y MÉTODOS}

Área de estudio. El presente estudio fue desarrollado en el área rural de los municipios de Armenia, Circasia, Quimbaya, Montenegro, Filandia, Calarcá y La Tebaida del Departamento del Quindío, los cuales hacen parte del área para priorizar acciones de control de la ENC. Cuenta con una capacidad instalada de 3.528.980 aves, representada en 83 granjas comerciales de aves de engorde, 25 de postura comercial y 3 de reproductoras, las cuales están incluidas en los programas de control oficial. Cuenta además con una planta de incubación, 5 explotaciones de avestruces, una de recría y una planta de beneficio de aves (Comunicación personal ICA-Seccional Quindío).

Animales y manejo. Se consideraron como aves de autoconsumo o de traspatio aquellas explotaciones con un número inferior de 200 animales. La población de traspatio se dividió en cuatro grupos productivos: a) Gallinas, aves dedicadas a la producción de huevo, b) Pollo, aves dedicadas a la producción de carne, c) Gallos, machos finos y criollos dedicados a la reproducción y/o riña, y d) Pavos.

Encuesta epidemiológica. Se realizó una delimitación geográfica del área y se definieron coordenadas de trabajo por medio de un estudio de georreferenciación previo efectuado por el ICA - Seccional Quindío. Se hizo un censo predio a predio en donde se definió una población conformada por 26.012 aves localizadas en 1.389 predios, de los cuales se seleccionó una muestra conformada por 465 establecimientos, a los cuales se les aplicó una encuesta epidemiológica que evaluó variables relacionadas con bioseguridad.

Recolección de muestras. Un total de 662 aves fueron muestreadas en el período comprendido entre mayo y julio de 2007, y junio y julio de 2008. Por medio de agujas estériles se obtuvieron 2 a $3 \mathrm{ml}$ de sangre por venopunción de la vena alar, que se depositaron en tubos de ensayo sin anticoagulante, se mantuvieron a temperatura ambiente en posición horizontal, hasta su traslado al laboratorio en un tiempo inferior a 6 horas. El suero separado fue transferido a tubos Eppendorf, se marcaron y se almacenaron en alícuotas bajo condiciones de congelación a $-20^{\circ} \mathrm{C}$ hasta su procesamiento en el laboratorio.

Ensayos inmunoenzimáticos ELISA. Se utilizó el kit FlockChek* NDV elaborado por IDEXX (E.U.). El procedimiento se realizó de acuerdo con las indicaciones del fabricante, con diluciones de los sueros de 1:500. Se consideraron como positivos los sueros con títulos superiores a 396.

Análisis estadístico. Para el presente estudio se realizó un análisis de varianza de una sola vía donde se compararon los títulos de anticuerpos obtenidos con la edad de los animales, mediante el programa estadístico MI NITAB, así mismo se evalúo la asociación entre las diferentes variables estudiadas y la seroreactividad por medio de la prueba de $\mathrm{X}^{2}$.

\section{RESULTADOS}

Caracterización de la población evaluada. Se analizaron 662 muestras de aves de traspatio distribuidas en su mayor proporción en el municipio de Circacia $41.2 \%$ $(n=273)$, seguido de Quimbaya $18.7 \%$ $(n=124)$, La Tebaida $15.9 \%(n=105)$, Calarcá $11.0 \%(n=73)$, Armenia $8.9 \%(n=59)$ y Montenegro $4.3 \%(n=28)$. El $87.5 \%$ de los animales muestreados correspondió al grupo de gallinas, el 1.7\%, 5.4\%, 5.4\% restantes, conformados por gallos, pavos y pollo de engorde respectivamente. Las aves presentaron edades comprendidas en un 
rango entre tres meses a cinco años, mantenidas en grupos entre cinco y veinte animales (Tabla 1 ).

Tabla 1. Distribución de las aves de traspatio por edad y grupos productivos en los siete municipios del eje cafetero estudiados.

\begin{tabular}{ccccccc}
\hline $\begin{array}{c}\text { Edad } \\
\text { (años) }\end{array}$ & \multicolumn{2}{c}{ Gallina Gallo Pavo Pollo } & $\mathbf{n}$ & $\%$ \\
\hline$<1$ & 344 & 5 & 13 & 29 & 391 & 59.1 \\
$>1-<2$ & 73 & 2 & 4 & 1 & 80 & 12.1 \\
$>2-<3$ & 14 & 0 & 0 & 1 & 15 & 2.3 \\
4 & 2 & 0 & 2 & 0 & 4 & 0.6 \\
5 & 49 & 1 & 8 & 0 & 58 & 8.8 \\
No Informa & 97 & 3 & 9 & 5 & 114 & 17.2 \\
\hline Total & 579 & 11 & 36 & 36 & 662 & 100.0 \\
\hline
\end{tabular}

Caracterización de los predios. Los predios incluidos en el estudio se caracterizaron por albergar en las mismas instalaciones aves de diferentes especies y edades en el 64.3\% (299/ 465). El sistema de manejo corresponde al tradicional en donde los animales se mantienen en condiciones de pastoreo, la alimentación se basa principalmente en concentrado, sobras de alimentos y maíz, así mismo, los animales no cuentan con asistencia médica veterinaria. No se encontró una asociación estadísticamente significativa entre las variables evaluadas y la presencia de anticuerpos anti-virus de ENC (Tabla 2).

Tabla 2. Factores potencialmente asociados con la presencia de anticuerpos anti-virus de ENC en la población de traspatio estudiada en el eje cafetero.

\begin{tabular}{|c|c|c|c|c|}
\hline Variable & $\begin{array}{c}\text { Total de } \\
\text { predios n (\%) }\end{array}$ & $\begin{array}{c}\text { Positivos } \\
\text { n (\%) }\end{array}$ & $\begin{array}{c}\text { Negativos } \\
\text { n (\%) }\end{array}$ & Valor $p$ \\
\hline Ubicación de las aves & & & & 0.36 \\
\hline 1. Pastoreo con cerco perimetral & $329(70.7)$ & $127(70.9)$ & $202(70.7)$ & \\
\hline 2. Pastoreo libre & $11(2.4)$ & $2(1.1)$ & $9(3.1)$ & \\
\hline 3. Jaula & $125(26.9)$ & $50(27.9)$ & $75(26.2)$ & \\
\hline Presencia de varias especies & & & & 0.85 \\
\hline 1. Si & $299(64.3)$ & $116(64.8)$ & $183(64)$ & \\
\hline 2. No & $166(35.7)$ & $63(35.2)$ & $103(36)$ & \\
\hline Origen de las aves & & & & 0.80 \\
\hline 1. Nacen en el predio & $334(71.8)$ & $126(70.4)$ & $208(72.7)$ & \\
\hline 2. Distribuidor comercial & $117(25.2)$ & $48(26.8)$ & $69(24.1)$ & \\
\hline 3. No informa & $14(3.01)$ & $5(2.8)$ & $9(3.1)$ & \\
\hline Disposición mortalidad & & & & 0.09 \\
\hline 1. Enterramiento & $357(76.8)$ & $140(78.2)$ & $217(75.9)$ & \\
\hline 2. Incineración & $13(2.8)$ & $8(4.5)$ & $5(1.7)$ & \\
\hline 3. Cielo abierto & $13(2.8)$ & $5(2.8)$ & $8(2.8)$ & \\
\hline 5. Alimento para animales & $1(0.2)$ & 0 & $1(0.3)$ & \\
\hline Disposición de la gallinaza & & & & 0.45 \\
\hline 1. Abono sin tratamiento & $459(98.7)$ & $178(99.4)$ & $281(98.3)$ & \\
\hline 2. Vende & $4(0.9)$ & $1(0.6)$ & $3(1)$ & \\
\hline 3. Cielo abierto & $2(0.5)$ & 0 & $2(0.7)$ & \\
\hline Desinfección & & & & 0.68 \\
\hline 1. Si & $102(21.9)$ & $41(22.9)$ & $61(21.3)$ & \\
\hline 2. No & $363(78.1)$ & $138(71.1)$ & $225(78.7)$ & \\
\hline
\end{tabular}


Seroprevalencia. La seroprevalencia de la ENC en el grupo de aves evaluadas fue del $30.7 \%(203 / 662)$, que correspondió al 38.5\% (179/465) de los predios muestreados. La prevalencia por grupos fue del 33.2\% (192/ $579), 16.7 \%(6 / 36), 11.1 \%(4 / 36)$ y $9.1 \%$ (1/11) en gallinas, pollos, pavos y gallos respectivamente, no constatándose asociación $(p=0.21)$ entre la especie y la seroprevalencia por la prueba de $\mathrm{X}^{2}$.

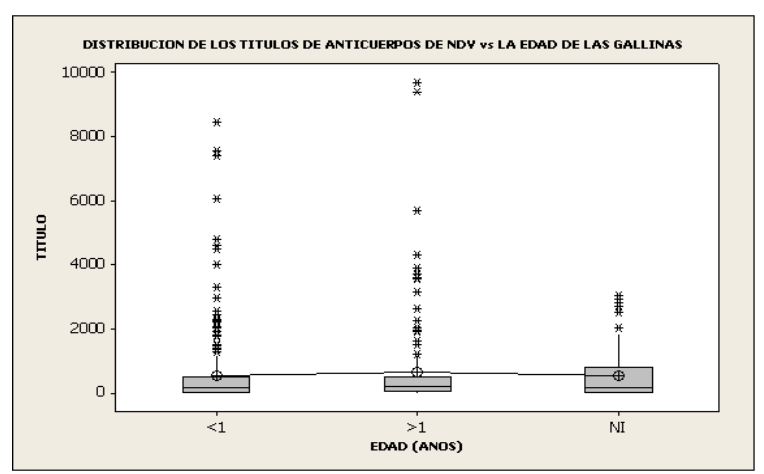

Figura 1. Distribución de los títulos de anticuerpos del virus de la ENC de acuerdo con la edad de las gallinas evaluadas.

El análisis de varianza en donde se comparó la distribución de los títulos de anticuerpos contra el virus de NC por grupos productivos y la edad, sugiere que no existe asociación entre estas dos variables en el grupo de gallinas $(p=0.49)$, gallos $(p=0.21)$, pollos $(p=0.1)$ y pavos $(p=0.075)$. Sin embargo, se observaron títulos de anticuerpos con valores extremos atípicos en el grupo de mayor representatividad en la población estudiada (Figura 1).

\section{DISCUSI ÓN}

Ninguna de las aves muestreadas tenía historia de vacunación previa contra ENC y se podría deducir que los anticuerpos IgG detectados en las aves de traspatio incluidas en el estudio serían el resultado de infección natural por el virus. La seroprevalencia de NC en el grupo de aves de traspatio evaluadas fue del $30.7 \%$ similar a la establecida en Australia (8) en 753 predios avícolas de traspatio y en Etiopia (4); pero inferior a los resultados obtenidos en estudios similares efectuados en Nigeria (9) por HI (51.9\%).
En la encuesta aplicada se pudo constatar que las aves de traspatio del área de estudio pueden permanecer en sus procesos productivos de postura o de engorde durante uno o cinco años en un sistema de manejo extensivo, caracterizado por la presencia de lotes de pequeño tamaño con animales de diferentes edades, similar al reportado en otros países de América y de África (2, 9, 10). Este hallazgo es importante, teniendo en cuenta que el incremento de la edad en los lotes tiene una relación directamente proporcional con la prevalencia de la ENC $(3,8)$. Es importante resaltar que en el presente estudio no se observó asociación entre los títulos de anticuerpos detectados por grupos y la edad de las aves de traspatio, sugiriéndose que tuvieron el mismo riesgo de contacto con el virus.

En el grupo de gallinas se evidenciaron títulos con valores extremos (Figura 1) que sugieren un desafío de campo, que puede atribuirse a factores como el sistema de manejo de producción tradicional que puede servir como un factor estresor y favorecer la infección; la continúa exposición a una gran variedad de agentes y a aves silvestres; las deficiencias de la nutrición; la ausencia de control de la enfermedad a través de la vacunación; el contacto de aves no infectadas con aves portadoras de patógenos, que pueden facilitar la propagación de enfermedades como ENC entre parvadas $(4,9)$.

La alta respuesta humoral detectada en las aves de los siete municipios evaluados, sugiere una continua presión de la infección en la población de traspatio (11) y pone de manifiesto la necesidad de implementar la vacunación de aves de traspatio adyacentes a las explotaciones comerciales, siendo necesario proponer un plan vacunal individual por la diversidad de edades encontradas en cada predio, teniendo mayor impacto la vacunación de aves menores de seis semanas de edad $(1,9,12)$. Esta medida de control de la ENC en el área es pertinente teniendo en cuenta que la legislación colombiana establece de carácter obligatorio la vacunación contra la ENC en todo tipo de aves con vacunas vivas (13) y por la proximidad de las explotaciones $(11,12)$. 
Este último aspecto ha sido identificado como factor de riesgo en la transmisión aérea del virus NC, que se favorece por el movimiento del personal, vehículos y fómites entre las granjas de traspatio y comerciales $(8,10$, 14). También se ha descrito que el éxito de esta ruta de transmisión depende de factores ambientales como la temperatura, humedad y la densidad de la población $(9,15)$, factores que se conjugan en la zona cafetera evaluada.

Se evidenció en el estudio una alta proporción de predios con diferentes especies de aves $(64.3 \%)$ como patos, pavos y aves ornamentales, las cuales han sido descritas como portadoras del virus de ENC, actuando como fuentes de infección para las gallinas comerciales y de traspatio $(2,10)$.

Se ha descrito la importancia del manejo de la gallinaza y la disposición de la mortalidad como medida de control de la $\operatorname{ENC}(2,6,16$, 17), porque el virus puede sobrevivir por largos períodos en las heces y en el agua mantenidas a temperaturas inferiores a $20^{\circ} \mathrm{C}$, así como en carcasas contaminadas (17). La transmisión de la ENC se puede efectuar por las heces cuando son transportadas a través de fómites manejados por el personal o por los equipos (17). Esta información es revelante teniendo en cuenta que en la zona evaluada el $99.2 \%$ de la gallinaza y pollinaza son manejadas como abono aplicado directamente sobre los cultivos de café o plátano, o se dispone a cielo abierto, sin ningún tipo de tratamiento que permita la inactivación de microorganismos, similar situación se presenta con el manejo de la mortalidad (Tabla 2).
Para fortalecer los programas de inspección, vigilancia y control de la ENC en el área de estudio se recomienda dar continuidad a los programas de vigilancia epidemiológica activa, seguimiento de los casos sospechosos para establecer la prevalencia, el modo de transmisión más importante de la enfermedad y definir poblaciones a riesgo; así como, capacitar e incentivar a los propietarios de aves de traspatio para que notifiquen los brotes de enfermedades que se presenten en sus predios e implementación de la vacunación masiva de todas las aves en el territorio nacional acorde con las políticas del ICA $(12,13)$.

En conclusión, es necesario el establecimiento de planes adecuados de vacunación de las aves de traspatio, la vigilancia epidemiológica activa, la observación de los casos sospechosos, sin dejar de lado la educación y capacitación, sobre el adecuado manejo de los animales, dirigida a los propietarios de las aves como medidas de control de la enfermedad.

\section{Agradecimientos}

A la Vicerrectoría de Investigaciones de la Universidad de Caldas y a la oficina del ICA Seccional Quindío, Colombia, por el financiamiento de esta investigación y al Semillero de Investigación en Nutrición y Salud de Monogástricos SINAS del Programa de Medicina Veterinaria y Zootecnia de la Universidad de Caldas.

\section{REFERENCIAS}

1. Ananth R, Kirubaharan JJ, Priyadarshini MLM, Albert A. Isolation of Newcastle disease viruses of high virulence in unvaccinated healthy village chickens in South India. Inter J Poult Sci 2008; 7(4): 368-3730.
2. Nwanta JA, Abdu PA, Exema WS. Epidemiology, challenges and prospects for control of Newcastle disease in Village poultry in Nigeria. Worlds Poult Sci J 2008; 64: 119-127. 
3. Alexander DJ. Newcastle disease and other avian paramyxoviruses. Rev Sci Tech 2000; 19 (2): 443-62.

4. Tadesse S, Ashenafi H, Aschalew Z. Seroprevalence study of Newcastle disease in local chickens in central Ethiopia. Intern J Appl Res Vet Med 2005; 3 (1): 25-29.

5. Thekisoe MMO, Mbati PA, Bisschop SPR. Different approaches to the vaccination of free ranging village chickens against Newcastle disease in Qwa-Qwa, South Africa. Vet Microbiol 2004; 101: 2330.

6. Documento Conpes 3468 de Política Nacional de Sanidad e Inocuidad para la cadena avícola. Departamento de Planeación Nacional. 30 de abril de 2007.

7. Ley 1255. Ley Avícola Nacional. Boletín oficial del Estado, número 47.187. Noviembre 28 de 2008.

8. East I, Kite V, Daniels P, Garner G. A cross-sectional survey of Australian chicken farms to identify risk factors associated with seropositivy to Newcastle-disease virus. Preventive Vet Med 2006; 77: 199-214.

9. Musa U, Abdu PA, Dafwang I, Umoh JU, Sa'idu L, Mera UM et al. Seroprevalence, seasonal occurrence and clinical manifestation of Newcastle disease in rural hosehold chickens in Plateau State, Nigeria. Inter J Poult Sci 2009; 8 (2): 200-204.

10. Ferrer R, Icochea E, Salas A, Alba M. Prevalencia de anticuerpos contra el virus de la enfermedad de Newcastle en gallus gallus de Lima. Estudio de caso-control. Rev Inv Vet Perú 2008; 19 (1): 67-74.
11. Zeleke A, Sori T, Gelaye E, Ayelet G. Newcastle disease in village chickens in the southern and Rift Valley districtis in Ethiopia. Inter J Poult Sci 2005; 4 (7): 507-510.

12. Henning J , Morton J, Pym R, Hla T, Meers $\mathrm{J}$. Evaluation of strategies to improve village chicken production-controlled field trials to assess effects of Newcastle disease vaccination and altered chick rearing in Myanmar. Prevent Vet Med 2009; 90: 17-30.

13. Resolución 01937, Medidas Sanitarias para la Prevención y el Control de la Enfermedad de Newcaslte. Boletín oficial del Estado, número 45260. Julio 23 de 2003.

14. Zanetti F, Berinstein A, Carrillo E. Effect of host selective pressure on Newcastle disease virus virulence. Microl Pathogen 2008; 44 : 135-140.

15. Li X, Chai T, Wang Z, Song C, Cao H, Liu $J$ et al. Ocurrence and transmission of Newcastle disease virus aerosol originating from infected chickens under experimental conditions. Vet Microbiol 2009; 136: 226-232.

16. Resolución 3283, Medidas Básicas de Bioseguridad de las Granjas Avícolas Comerciales. Boletín oficial del Estado, número 47.122. Septiembre 22 de 2008.

17. Guan J, Chan M, Ma B, Grenier C, Wilkie DC, Pasick J et al. Development of methods for detection and quantification of avian influenza and Newcastle disease viruses in compost by real-time reverse transcription polymerase chain reaction and virus isolation. Poult Sci J 2008; 87(5): 838843. 